\title{
Estimating the effects of pile driving sounds on seals: Pitfalls and possibilities
}

Katherine F. Whyte, Debbie J. F. Russell, Carol E. Sparling, Bas Binnerts, and Gordon D. Hastie

Citation: The Journal of the Acoustical Society of America 147, 3948 (2020); doi: 10.1121/10.0001408

View online: https://doi.org/10.1121/10.0001408

View Table of Contents: https://asa.scitation.org/toc/jas/147/6

Published by the Acoustical Society of America

\section{ARTICLES YOU MAY BE INTERESTED IN}

Real-time observations of the impact of COVID-19 on underwater noise

The Journal of the Acoustical Society of America 147, 3390 (2020); https://doi.org/10.1121/10.0001271

Animal-borne tags provide insights into the acoustic communication of southern right whales (Eubalaena australis) on the calving grounds

The Journal of the Acoustical Society of America 147, EL498 (2020); https://doi.org/10.1121/10.0001391

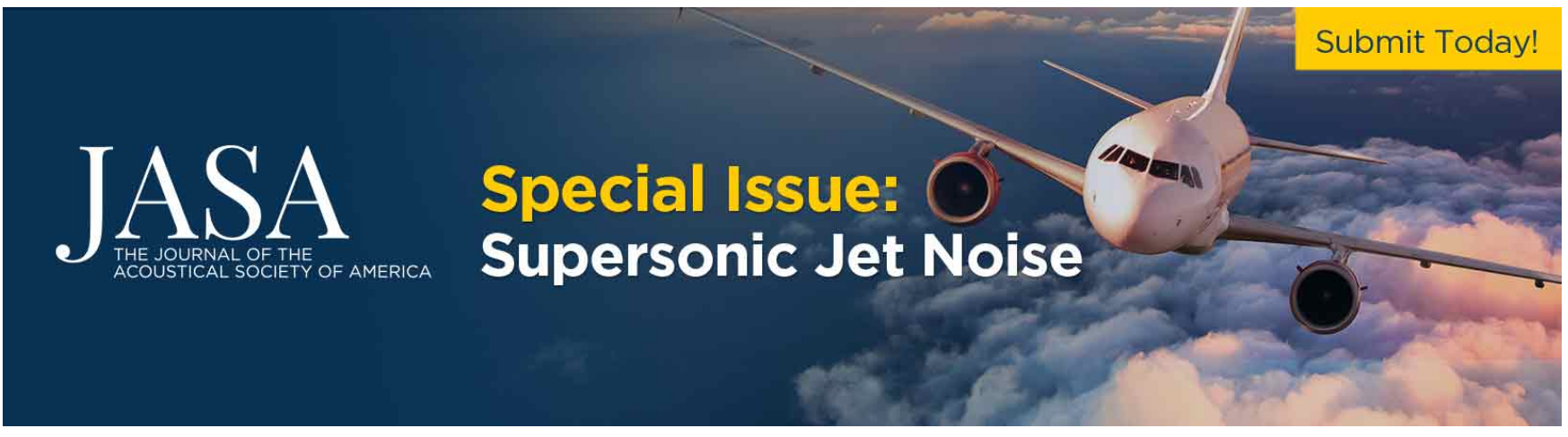




\title{
Estimating the effects of pile driving sounds on seals: Pitfalls and possibilities ${ }^{\text {a) }}$
}

\author{
Katherine F. Whyte, ${ }^{1, \mathrm{~b}), \mathrm{c})}$ Debbie J. F. Russell, ${ }^{1, \mathrm{c}), \mathrm{d})}$ Carol E. Sparling, ${ }^{2, \mathrm{e})}$ Bas Binnerts, $^{3}$ \\ and Gordon D. Hastie ${ }^{1, f)}$ \\ ${ }^{1}$ Sea Mammal Research Unit, Scottish Oceans Institute, University of St Andrews, St Andrews, Fife, KY16 8LB, United Kingdom \\ ${ }^{2}$ SMRU Consulting, Scottish Oceans Institute, University of St Andrews, St Andrews, Fife, KY16 8LB, United Kingdom \\ ${ }^{3}$ TNO, Acoustics and Sonar expertise group, Oude Waalsdorperweg 63, 2597 AK, The Hague, Netherlands
}

\begin{abstract}
:
Understanding the potential effects of pile driving sounds on marine wildlife is essential for regulating offshore wind developments. Here, tracking data from 24 harbour seals were used to quantify effects and investigate sensitivity to the methods used to predict these. The Aquarius pile driving model was used to model source characteristics and acoustic propagation loss $(16 \mathrm{~Hz}-20 \mathrm{kHz})$. Predicted cumulative sound exposure levels (SELcums) experienced by each seal were compared to different auditory weighting functions and damage thresholds to estimate temporary (TTS) and permanent (PTS) threshold shift occurrence. Each approach produced markedly different results; however, the most recent criteria established by Southall et al. [(2019) Aquat. Mamm. 45, 125-232] suggests that TTS occurrence was low (17\% of seals). Predictions of seal density during pile driving made by Russell et al. [(2016) J. Appl. Ecol. 53, 1642-1652] were compared to distance from the wind farm and predicted single-strike sound exposure levels (SELss) by multiple approaches. Predicted seal density significantly decreased within $25 \mathrm{~km}$ or above SELss (averaged across depths and pile installations) of $145 \mathrm{~dB} r e 1 \mu \mathrm{Pa}^{2} \cdot s$. However, there was substantial variation in SELss with depth and installation, and thus in the predicted relationship with seal density. These results highlight uncertainty in estimated effects, which should be considered in future assessments.
\end{abstract}

(C) 2020 Acoustical Society of America. https://doi.org/10.1121/10.0001408

(Received 31 December 2019; revised 18 May 2020; accepted 27 May 2020; published online 16 June 2020)

[Editor: Colleen Reichmuth]

Pages: $3948-3958$

\section{INTRODUCTION}

In order to meet ambitious climate change targets, the demand for renewable energy is increasing and bringing substantial industrial activity to marine environments. In particular, the number, size, and capacity of offshore wind farms has been growing rapidly and is expected to continue to increase (Bailey et al., 2014; Breton and Moe, 2009). This expansion has been particularly prevalent in European waters, where there are currently more than 4500 gridconnected offshore wind turbines across eleven countries, equivalent to a capacity of $18499 \mathrm{MW}$ (WindEurope, 2019).

In predicting and assessing the environmental impact of these offshore wind farms on the surrounding marine life, one of the key uncertainties is the potential effects of underwater construction noise. Of particular concern are the effects of high intensity sounds produced during pile driving, where brief impulsive sounds with source levels of up

\footnotetext{
a) This paper is part of a special issue on The Effects of Noise on Aquatic Life.

b)Electronic mail: kfw5@st-andrews.ac.uk, ORCID: 0000-0003-3388-9603.

${ }^{c}$ Also at: Centre for Research into Ecological and Environmental Modelling, The Observatory, University of St Andrews, St Andrews, Fife, KY16 9LZ, UK

d) ORCID: 0000-0002-1969-102X.

e) ORCID: 0000-0001-7658-5111.

${ }^{\text {f) }}$ ORCID: 0000-0002-9773-2755.
}

to $250 \mathrm{~dB}$ re $1 \mu \mathrm{Pa} @ 1 \mathrm{~m}$ (peak-peak) can be produced every 1-2 s (Bailey et al., 2010). The at-sea movements of harbour seals (Phoca vitulina) overlap with many areas of current and proposed development (Russell et al., 2014; Sharples et al., 2012), and so there are concerns that these sounds may damage hearing, elicit overt behavioural responses, and/or exclude seals from areas of their natural habitat (Hastie et al., 2015; Russell et al., 2016; Thompson et al., 2013). To accurately predict the effects of pile driving and determine how these could be mitigated, it is critical to understand the nature and severity of these potential effects and the sound levels at which they occur.

Estimating the effects of anthropogenic noise on marine mammal hearing can be challenging. Using available data on hearing sensitivities and hearing damage across species, Southall et al. (2007) derived estimates of the minimum noise exposure required for the onset of temporary (TTS) and permanent (PTS) threshold shifts in hearing sensitivity. They also generated a series of frequency-weighted hearing sensitivity curves for different functional groups of marine mammals (M-weightings). For pinnipeds underwater, TTS was predicted to occur at M-weighted 24-h cumulative sound exposure levels (SELcum) of $171 \mathrm{~dB}$ re $1 \mu \mathrm{Pa}^{2} \cdot \mathrm{s}$ and PTS at $186 \mathrm{~dB}$ re $1 \mu \mathrm{Pa}^{2} \cdot \mathrm{s}$ for impulsive sounds such as pile driving. These weighting functions and TTS/PTS thresholds were subsequently updated in 2019 , incorporating the most 
recent scientific information on hearing abilities and auditory damage for each marine mammal species group (Southall et al., 2019). In general for pinnipeds, these new weightings were slightly less conservative. Pinnipeds were also subdivided into two groupings (phocids, otariids); for phocid pinnipeds in water, the SELcum thresholds for impulsive sounds are now estimated to be 170 and $185 \mathrm{~dB}$ re $1 \mu \mathrm{Pa}^{2} \cdot \mathrm{s}$ for TTS and PTS, respectively. It should be noted that for seals the weighting functions and TTS/PTS thresholds for impulsive sounds described in Southall et al. (2019) are the same as those provided by the US National Marine Fisheries Service (NMFS, 2016, 2018). Faulkner et al. (2019) simulated how these two different criteria may alter the predicted effect zones from a variety of modelled noise sources, comparing the relative differences between Southall et al. (2007) and Southall et al. (2019). For phocids, they concluded that the more recent weighting functions are likely to substantially reduce the estimated range of PTS risk (e.g., from approximately $10 \mathrm{~km}$ to $2 \mathrm{~km}$ for a theoretical scenario involving pile driving 24-h SELcums at offshore wind farms in the North Sea) (Faulkner et al., 2019).

A limited number of studies have investigated the effects of pile driving sounds on harbour seal hearing and behaviour. Recent playbacks of broadband piling sounds [ 500-800 Hz, single-strike sound exposure level (SELss) of $152 \mathrm{~dB}$ re $1 \mu \mathrm{Pa}^{2} \cdot \mathrm{s}$ at $1 \mathrm{~m}$ depth, $2 \mathrm{~m}$ from the source] were found to cause onset of TTS at unweighted SELcums of around $192 \mathrm{~dB}$ re $1 \mu \mathrm{Pa}^{2} \cdot \mathrm{s}$ in two harbour seals in captivity (Kastelein et al., 2018). Small TTSs (2-4 dB) occurred in that experiment and hearing recovered within $60 \mathrm{~min}$. However, in the wild, animals may encounter pile driving sounds at higher received levels than that tested therein. Two studies (Hastie et al., 2015; Russell et al., 2016) investigated the predicted sound exposure and at-sea behaviour of tagged harbour seals near pile driving activity at an offshore wind farm. Hastie et al. (2015) calculated predictions of auditory injury in each tagged seal as a result of exposure to piling sounds. The analysis showed that half of the tagged animals received predicted M-weighted 24-h SELcums that would cause PTS [based on Southall et al. (2007)]. In addition, there was a significant reduction in seal density up to $25 \mathrm{~km}$ from the wind farm during periods of piling activity, relative to non-piling periods (Russell et al., 2016). The magnitude of the observed reduction decreased with increasing distance from the piling location, and recovery time was relatively short, with seal density returning to pre-piling levels within two hours of the cessation of piling.

Although both of these findings represented an important step forward in our understanding, the direct application of these results in Environmental Impact Assessments (EIAs) may be challenging. For example, since estimates of piling sound exposure (Hastie et al., 2015) were completed, updated auditory weighting functions and thresholds for the onset of hearing damage have been published (Southall et al., 2019). Further, to contextualise predicted changes in density over space, Russell et al. (2016) illustrated how seal density changed in relation to distance from the middle of the wind farm and in relation to predicted SELs (averaged across all pile installations) for the loudest and quietest parts of the water column. However, although not explicitly stated, both of the relationships (distance and SEL) presented in Russell et al. (2016) represent the expected change in seal density for cumulatively increasing zones around pile driving. For example, the presented change in seal density at $20 \mathrm{~km}$ represents the change for all spatial cells within $20 \mathrm{~km}$ of the wind farm, and seal density at $40 \mathrm{~km}$ represents the change for all cells within $40 \mathrm{~km}$. These results could be misinterpreted and such cumulative predictions are not particularly appropriate for the finer scale quantitative analyses often required to inform EIAs. The predicted change in seal density for any given location also reflected a wide range of predicted SELs (across depths and pile installations). To address these potential issues and make the results more applicable to EIAs, we use the seal tag data from the previous studies to (1) compare how estimates of SELcum and auditory damage may differ when different weighting functions are applied to them; (2) quantify the relationship between predicted seal density change and distance/SEL for both cumulative and annulus zones; (3) compare five different approaches to combining SELs across pile installations and depths; and (4) investigate the robustness of these relationships.

\section{METHODS}

\section{A. Seal tag data}

In January 2012, harbour seals were caught on or near haulout sites on intertidal sandbanks in The Wash, southeast England, UK. To record the movements and dive behaviour of seals around active pile driving, all animals were fitted with a SMRU Instrumentation GPS telemetry tag (hereafter GPS/GSM tags; SMRU Instrumentation, University of St Andrews, Fife, UK). Seals were first anesthetized using Zoletil ${ }^{\circledR}$ or Ketaset ${ }^{\circledR}$ in combination with Hypnovel $^{\circledR}$, and GPS/GSM tags were attached to the fur at the back of the neck using a fast-setting two-part epoxy adhesive or Loctite ${ }^{\circledR} 422$ Instant Adhesive. All seal handling and procedures were carried out under Home Office Licence 60/4009.

Out of the 25 deployed tags in The Wash, three tags collected data for less than two days and so were excluded from further analyses. Two seals from a concurrent study approximately $200 \mathrm{~km}$ to the south (in the Thames) moved into The Wash during pile driving, and so were included in the dataset. This resulted in a total sample size of 24 individuals (11 males, 13 females) (details provided in Electronic Supporting Information ${ }^{1}$ ).

The tags provided GPS locations approximately every $15 \mathrm{~min}$, as well as nine depth data points per dive and records of all haulout times. The data were cleaned and erroneous locations removed based on thresholds of residual error and the number of satellites. For more details of the 
data collection and study site, see Hastie et al. (2015) and Russell et al. (2016).

\section{B. Pile driving}

Operational data on pile driving at Lincs offshore wind farm were provided by Centrica plc. Throughout the period of the 2012 seal tag deployment, 27 monopiles were installed at Lincs by pile driving between 28 January and 11 May 2012 (Table I). A total of 77968 piling strikes occurred during the study with a mean strike energy of 1202 $(\mathrm{SD}=613) \mathrm{kJ}$. For further information on the pile driving, see Hastie et al. (2015).

Opportunistic recordings of pile driving were available from two sources: an autonomous moored sound recorder (DSG-Ocean Acoustic Datalogger; Loggerhead Instruments, Sarasota, FL, USA) at $\sim 9 \mathrm{~m}$ depth and a range of $4900 \mathrm{~m}$ from the pile driving location, and a series of boat-based recordings at $\sim 1 \mathrm{~m}$ depth between 1000 and $9500 \mathrm{~m}$ from pile driving [using a Reson TC 4014 hydrophone with a Brüel and Kjaer amplifier (type 2635) and a calibrated Avisoft Ultrasoundgate 416 digital acquisition system at a sample rate of $192 \mathrm{kHz}$; for further information, see Hastie et al. (2015)]. These recordings covered the full range of pile driving blow energies and were compared to the estimates made using the acoustic models.

\section{Acoustic modelling}

To estimate the sound levels resulting from the piling across the study area, a series of acoustic modelling approaches were carried out. The Aquarius pile driving model [for detailed description of the model and its validation, see de Jong et al. (2019)] was used to model source characteristics and acoustic propagation loss. Note that this is a different sound propagation modelling approach to the one used by Hastie et al. (2015) and Russell et al. (2016).

TABLE I. List of parameters used for the percussive pile driving source modelling.

\begin{tabular}{lc}
\hline \hline Parameter & Value \\
\hline Pile diameter & 5.2 metres \\
Wall thickness & $58.35 \mathrm{~mm} *$ \\
& *estimated using API equation: \\
& $\mathrm{D}$ (diameter) $=5,200 \mathrm{~mm}$ \\
Pile material properties & Material: Steel \\
& Density $\rho: 7,850 \mathrm{~kg} / \mathrm{m}^{3}$ \\
& Elasticity E: $210 \mathrm{GPa}$ \\
Compressional sound speed c $: 5,172 \mathrm{~m} / \mathrm{s}$ \\
Poisson ratio $v: 0.3$ \\
Range of strike energies & 54 to $2,035 \mathrm{~kJ}$ \\
Hammer type & MHU $1900 \mathrm{~S}$ \\
Ram mass & 95 ton \\
Anvil mass & 31 ton \\
Contact stiffness & $20 \mathrm{GPa}$ \\
Frequency range modelled & $16 \mathrm{~Hz}$ to $20 \mathrm{kHz}$ \\
\hline \hline
\end{tabular}

The Aquarius model uses information on the properties of the hammer and the pile (Table I) to determine a source excitation spectrum using the model described by Deeks and Randolph (1993). This source spectrum is integrated into a range dependent propagation model [normal mode based adiabatic propagation model using the KrakenC (Porter, 2001) model to compute the propagating modes] to predict acoustic propagation loss across the study area, incorporating information on seabed characteristics and water depth. Here, the bathymetry was set to Mean Sea Level (MSL) and the modelled receiver resolution was chosen equal to $1 \mathrm{~m}$, which leads to a smooth solution with depth such that linear interpolation can be used to obtain the received levels at intermediate depth. The seabed was assumed to be homogeneous, with properties corresponding to medium sand (grain size parameter $\Phi=1.5$ ) obtained from Table 4.18 in Ainslie (2010). This was the most common value in the considered modelling area, using data from the EMODnet Bathymetry Data Portal. The properties of the water column were set at a compressional sound speed of $1500 \mathrm{~ms}^{-1}$ and a density of $1024 \mathrm{~kg} / \mathrm{m}^{3}$, and the Thorp attenuation model was used for volume attenuation (Ainslie, 2010; Sehgal et al., 2009). It should be noted that the effects of losses due to sea surface scattering and absorption were not considered for the purposes of the modelling.

Depth explicit model predictions were output as estimated single strike sound exposure levels $\left(\mathrm{SEL}_{\mathrm{ss}, \mathrm{ref}}, \mathrm{dB}\right.$ re 1 $\left.\mu \mathrm{Pa}^{2} \cdot \mathrm{s}\right)$ at a reference strike energy of $1000 \mathrm{~kJ}$ across a series of spatial grids within the study area at $\sim 279 \mathrm{~m}$ resolution (Longitude: from $-1^{\circ}$ to $3^{\circ}$ with a $15 \mathrm{~s}$ resolution, Latitude: from $52^{\circ}$ to $55^{\circ}$ with a $9 \mathrm{~s}$ resolution). Individual grids were produced for each $2.5 \mathrm{~m}$ depth bin (from 2.5 to $107.5 \mathrm{~m}$ depth); sound levels below the seabed were indicated by a "NaN" value. Model predictions included estimated SELss with three different frequency weightings applied to them; these were (i) unweighted, (ii) Pinnipeds-in-Water Mweighted $\left(\mathrm{M}_{\mathrm{pw}}\right)$ (Southall et al., 2007), and (iii) Phocids-inWater weighted (PCW) (Southall et al., 2019). Frequencies from $16 \mathrm{~Hz}$ to $20 \mathrm{kHz}$ were modelled, using third octave centre frequency bands.

\section{Acoustic exposure of the tagged seals}

The tag data consisted of a series of time-stamped GPS locations when the seal was at the water surface. Further, during each dive, the tag provided dive depths at nine points distributed equally in time throughout each dive. As seal depths were derived from pressure sensor readings on board the tag, they were measured relative to the water surface, leading to a potential mismatch with the original bathymetry data, which were relative to chart datum at the Lowest Astronomical Tide (LAT). Water depths relative to Mean Sea Level (MSL) were derived by applying the United Kingdom Hydrographic Office Vertical Offshore Reference Frame (VORF) Lowest Astronomical Tide (LAT) correction (Iliffe et al., 2013) for the study area. These water depths at 
MSL were used for the acoustic modelling and corresponding received levels for seals.

During periods of pile driving, tracks of seals were linearly interpolated between successive GPS locations to provide estimated locations of seals at the estimated time-ofarrival of sound from each pile driving strike (assuming a sound speed of $1500 \mathrm{~ms}^{-1}$ ). Similarly, dive depths at each of these interpolated locations were estimated through linear interpolation between successive measured dive depths. Together, these provided the estimated 3D locations of each seal at the time it received the sound from all pile driving strikes for each piling location.

Each seal 3D location was matched to the corresponding spatial grid cell and the closest $2.5 \mathrm{~m}$ depth bin (from 2.5 to $107.5 \mathrm{~m}$ depth) in the acoustic model, and the received $\mathrm{SEL}_{\mathrm{ss}, \mathrm{ref}}$ was identified based on propagation loss estimates at the associated location and depth for each individual pile driving pulse. Information on the blow energy of each strike was then used to scale the modelled reference $\mathrm{SEL}_{\mathrm{ss}, \mathrm{ref}}$ (at $1000 \mathrm{~kJ}$ strike energy) to obtain final estimates of received SELss at each seal 3D location. This was carried out through energetic (broadband) scaling of the SELss spectrum using Eq. (1) to calculate the value that is added to the modelled $\mathrm{SEL}_{\mathrm{ss}, \mathrm{ref}}$ :

$$
S E L_{s s}=S E L_{s s, r e f}+10 \log _{10} \frac{E}{E_{r e f}},
$$

where $\mathrm{E}$ is the energy $(\mathrm{kJ})$ of the pile driving strike, $\mathrm{E}_{\mathrm{ref}}$ is the reference strike energy $(1000 \mathrm{~kJ}), \mathrm{SEL}_{\mathrm{ss}, \text { ref }}$ is the modelled single strike sound exposure level at the reference strike energy, and SELss is the resulting scaled single strike sound exposure level ( $\mathrm{dB}$ re $\left.1 \mu \mathrm{Pa}^{2} \cdot \mathrm{s}\right)$.

\section{E. Predictions of auditory damage}

Auditory damage (in the form of hearing threshold shifts) was predicted for each tagged seal using three approaches. These were based on: 1) a threshold based on results from previous studies of TTS onset in harbour seals as a result of exposure to pile driving sounds (Kastelein et al., 2018) (unweighted); 2) the approach developed by Southall et al. (2007) for evaluating the likelihood of TTS and PTS in pinnipeds exposed to anthropogenic sound $\left(\mathrm{M}_{\mathrm{pw}}\right)$; and 3) the updated approach described by Southall et al. (2019) for evaluating the likelihood of TTS and PTS in phocid seals exposed to anthropogenic sound (PCW). Previously, Hastie et al. (2015) used approach 2) to estimate the potential for auditory damage in tagged seals as a result of exposure to pile driving sounds during the installation of the Lincs offshore wind farm.

For each seal, estimated received SELss were summed over each 24-h period (Julian day) containing pile driving to calculate the 24-h SELcum under each method (unweighted, $\mathrm{M}_{\mathrm{pw}}$, and PCW):

$$
\text { SELcum }=10 \log _{10}\left\{\sum_{n=1}^{N} 10^{S E L_{n} / 10}\right\},
$$

where SELcum is the cumulative sound exposure level of all $N$ piling strikes within the 24-h period, and $\mathrm{SEL}_{\mathrm{n}}$ is the received SELss for each piling strike $n$. For the purposes of estimating auditory threshold shifts, an 'effective quiet' value of $124 \mathrm{~dB}$ re $1 \mu \mathrm{Pa}$ (Finneran, 2015) was assumed [the highest sound pressure level (SPL) of a sound that will neither produce significant TTS nor retard recovery from TTS from prior exposure to a higher level]. Each 24-h SELcum was then compared to published TTS and PTS onset thresholds under each approach (Table II). It should be noted that, although the $\mathrm{M}_{\mathrm{pw}}$ and PCW weightings are based on exposure during a 24-h period, the unweighted criteria (Kastelein et al., 2018) is based on the threshold at which TTS was observed at two hearing frequencies ( 4 and $8 \mathrm{kHz}$ ) in a $6-\mathrm{h}$ experimental setting.

\section{F. Changes in seal density in relation to pile driving}

Russell et al. (2016) generated population-level predictions of the at-sea density of seals during piling and breaks in piling. The movements of individual seals in response to piling were not modelled directly. These population-level predictions were based on analyses of 23 of the tagged harbour seals [individual pv42-194-12 was excluded as in one trip it travelled much further than the other individuals, leading to issues in specifying the accessible spatial area for all seals; see Russell et al. (2016) for details]. The analyses were restricted to return trips from haulouts within The Wash and comprised a use-availability design within a generalised estimating equation (GEE) framework. This approach was used as it enabled the study to consider the entire accessible area for seals in The Wash, and model seal density in an area with a complex coastline. The GEE approach also enabled generation of uncertainty estimates robust to the presence of residual autocorrelation within individuals. Once the optimal models for seal density during piling and non-piling periods were fit, the differences in these two distributions on a $5 \times 5 \mathrm{~km}$ resolution ( 867 spatial

TABLE II. List of thresholds used to estimate auditory damage in harbour seals exposed to pile driving sounds. Shown are the cumulative sound exposure levels (SELcum, dB re $1 \mu \mathrm{Pa}^{2} \cdot \mathrm{s}$ ) estimated to cause temporary (TTS) or permanent (PTS) threshold shifts in hearing, using three different methods of weighting sound frequencies. The $\mathrm{M}_{\mathrm{pw}}$ and PCW weightings are based on exposure during a 24-h period, whereas the unweighted threshold is based on observed TTS in a 6-h experimental setting.

\begin{tabular}{lcc}
\hline \hline Frequency weighting method & TTS threshold & PTS threshold \\
\hline Unweighted & 192 & Reference \\
M $_{\text {pw weighted (M-weighted, Pinnipeds in Water) }}$ & 171 & 186 \\
PCW weighted (Phocids in Water) & 170 & 185 \\
\hline \hline
\end{tabular}


cells) were quantified, and predictions of percentage of the at-sea population in each cell were made. A parametric bootstrap from the GEE model was used to calculate the 95\% confidence intervals (CIs) for both the predicted density (percentage of the at-sea population) and predicted percentage change in density (non-piling to piling).

Here, we compare how the predicted percentage change in seal density (between non-piling and piling) relates to both the distance from the centre of Lincs wind farm and the predicted received SELss at each cell location. Predictions could not be made relative to the exact piling locations as, for the GEE model, seal location data were pooled across piling events and so contained several different piling locations. In Russell et al. (2016), the presented relationship was in cumulative zones of increasing distance: each increment represents all cells equal or less than that distance (e.g., the predicted change in seal density value at $40 \mathrm{~km}$ represents the change in all cells within a distance of $\leq 40 \mathrm{~km}$ from the wind farm). Here, we also quantify how this relationship changes in annulus zones with $5 \mathrm{~km}$ increments: each increment represents the previous $5 \mathrm{~km}$ (e.g., the predicted change in seal density value at $40 \mathrm{~km}$ represents the mean for all cells with distances of 35 to $40 \mathrm{~km}$ ). We also quantify the relationship between predicted seal density and received SELss for both cumulative and annulus approaches. In cumulative zones, the predicted change in density at $135 \mathrm{~dB}$ re $1 \mu \mathrm{Pa}^{2} \cdot \mathrm{s}$ represents the change in all cells with a received level of $\geq 135 \mathrm{~dB}$ re $1 \mu \mathrm{Pa}^{2} \cdot \mathrm{s}$. In annulus zones, the predicted change in density at $135 \mathrm{~dB}$ re $1 \mu \mathrm{Pa}^{2} \cdot \mathrm{s}$ represents the change for all cells with estimated SELss of 135 to $140 \mathrm{~dB}$ re $1 \mu \mathrm{Pa}^{2} \cdot \mathrm{s}$. In both the distance and SELss relationships, the first zone (that closest to the wind farm) is the same between cumulative and annulus approaches [e.g., 0-5 km (annulus) is the same as $\leq 5 \mathrm{~km}$ (cumulative); $175-180 \mathrm{~dB}$ re $1 \mu \mathrm{Pa}^{2} \cdot \mathrm{s}$ (annulus) is the same as $\geq 175 \mathrm{~dB}$ re $1 \mu \mathrm{Pa}^{2} \cdot \mathrm{s}$ (cumulative)]. The approaches differ in how the subsequent estimates are calculated, with the annulus approach looking at seal density in each distance/SELss increment, and the cumulative approach increasing the zone size each time by adding in seal densities at larger distances/lower SELss. The cumulative predictions were repeated here for clear comparison with the annulus zones, as previous results in Russell et al. (2016) used a different acoustic propagation model. By both annulus and cumulative approaches, it was necessary to consider estimated received levels across piling events and depths. Therefore, the outputs of acoustic models for each of the 27 piling locations had to be combined. To investigate the relationship between percentage change in density and estimated SELss, we used five approaches to combining SELss across piles and depths:

(1) Mean SELss (averaged across depths and the 27 piles) (Fig. 2).

(2) Lower 95\% CI of SELss across piles (averaged across depths) (Fig. S2).

(3) Upper 95\% CI of SELss across piles (averaged across depths) (Fig. S3).
(4) SELss at the quietest depths (averaged across piles) (Fig. S4).

(5) SELss at the loudest depths (averaged across piles) (Fig. S5).

For each of these approaches, we considered a single blow energy of $2000 \mathrm{~kJ}$ (the maximum energy reached in each piling event [Eq. (1)], and all SELss were averaged onto a $5 \times 5 \mathrm{~km}$ grid. Measurements by Nedwell et al. (2011) of ambient noise in The Wash during construction of Lincs wind farm estimated a median ambient sound level of $118 \mathrm{~dB}$ re $1 \mu \mathrm{Pa}^{2} \cdot \mathrm{s}$, and so any estimated SELss below this value were assigned to $118 \mathrm{~dB}$ re $1 \mu \mathrm{Pa}^{2} \cdot \mathrm{s}$. Following Russell et al. (2016), a parametric bootstrap of the GEE model was used to calculate $95 \%$ confidence intervals (CIs) for each zone; these CIs represent the uncertainty resulting from the distribution model (i.e., they do not incorporate any uncertainty in received sound levels).

All additional analyses [to that conducted for Hastie et al. (2015) and Russell et al. (2016)] were carried out using R (R Core Team, 2019) within packages maptools (Bivand and Lewin-Koh, 2017), raster (Hijmans, 2017), rgdal (Bivand et al., 2014) and sp (Pebesma and Bivand, 2005).

\section{RESULTS}

\section{A. Acoustic exposure of the tagged seals}

Comparison of the measured SELss from the recordings of pile driving showed that median absolute error in SELss across all measured piling blows was $4 \mathrm{~dB}$ re $1 \mu \mathrm{Pa}^{2} \cdot \mathrm{s}$ (Fig. S6). In general, errors were higher for the boat-based measurements made close to the surface (median absolute error $=14 \mathrm{~dB}$ re $\left.1 \mu \mathrm{Pa}^{2} \cdot \mathrm{s}\right)$, compared to those from the moored recorder (median absolute error $=3 \mathrm{~dB}$ re $1 \mu \mathrm{Pa}^{2} \cdot \mathrm{s}$ ).

During the seal tag deployment, the maximum estimated unweighted SELss at individual seals varied from 113 to $173 \mathrm{~dB}$ re $1 \mu \mathrm{Pa}^{2}$.s. The maximum SELss (173 dB re $1 \mu \mathrm{Pa}^{2} \cdot \mathrm{s}$ ) occurred for seal 'pv40-268-12' (Fig. 1) at a range of $4.7 \mathrm{~km}$ and a dive depth of $23.6 \mathrm{~m}$. For further details of acoustic exposure of each tagged seal, see Electronic Supporting Information (Fig. S1).

\section{B. Predictions of auditory damage}

The use of each weighting function resulted in markedly different SELcum estimates from pile driving (Table III). In general, unweighted SELcum were highest (as it is unweighted, none of the sound is filtered) and PCWweighted SELcum (Southall et al., 2019) were lowest.

Predicted unweighted SELcum from pile driving varied between tagged seals (Table III) with maximum SELcum for each seal ranging from 153 to $200 \mathrm{~dB}$ re $1 \mu \mathrm{Pa}^{2} \cdot \mathrm{s}$. It was predicted that five $(21 \%)$ of the seals did not receive any SELss above the assumed level of effective quiet $(124 \mathrm{~dB}$ re $1 \mu \mathrm{Pa})$. Three $(13 \%)$ of the seals exceeded unweighted sound levels (192 dB re $1 \mu \mathrm{Pa}^{2} \cdot \mathrm{s}$ ) previously shown to result in TTS in harbour seals exposed to pile driving sounds (Table II). The closest approach distance to pile driving for each of these three seals was between 3.9 and $5.0 \mathrm{~km}$ (Table III). 

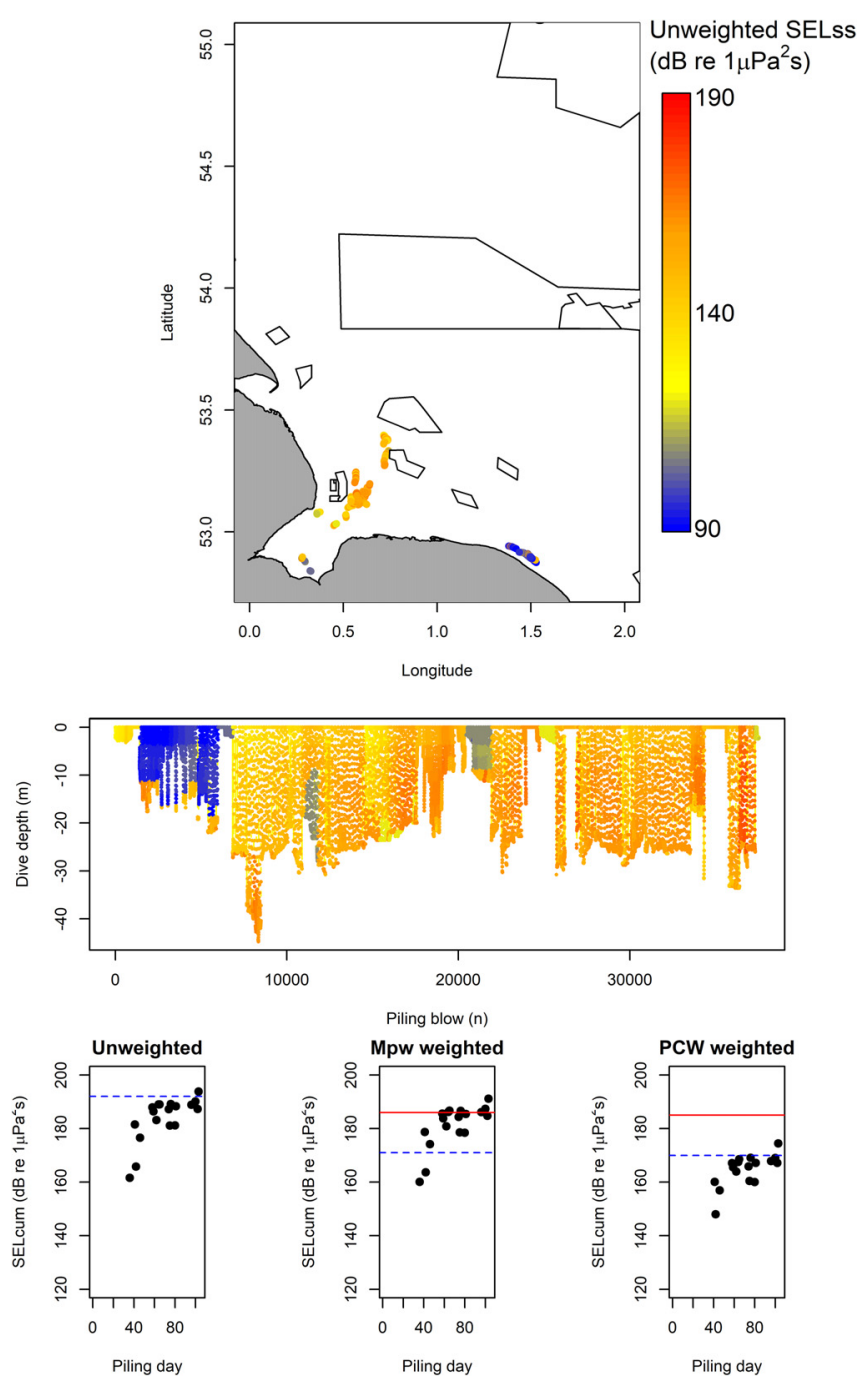

FIG. 1. (Color online) Example of the estimated acoustic exposure from pile driving at one of the tagged harbour seals (ID\#: pv40.268.12). The figure shows the estimated locations of the seal (top panel) and the dive depth (middle panel) of the seal at the times it received the sound from each piling strike. The points in both panels have been colour coded by estimated unweighted single strike Sound Exposure Levels (SELss; dB re $1 \mu \mathrm{Pa}^{2} \cdot \mathrm{s}$ ). The lower panels show the estimated cumulative sound exposure levels (SELcum; $\mathrm{dB}$ re $1 \mu \mathrm{Pa}^{2} \cdot \mathrm{s}$ ) to the tagged seal for each $24 \mathrm{~h}$ period, including the unweighted SELcums, M-weighted $\left(\mathrm{M}_{\mathrm{pw}}\right)$ SELcums (Southall et al., 2007), and PCW-weighted SELcums (Southall et al., 2019). The estimated onset thresholds for TTS (dashed line) and PTS (solid line) are shown for each weighting.

Predicted $\mathrm{M}_{\mathrm{pw}}$-weighted SELcum (Southall et al., 2007) varied between individual seals (Table III) with maximum SELcum $\left(\mathrm{M}_{\mathrm{pw}}\right)$ ranging from 150 to $197 \mathrm{~dB}$ re $1 \mu \mathrm{Pa}^{2} \cdot$ s. Five $(21 \%)$ of the seals did not receive any SELss $\left(\mathrm{M}_{\mathrm{pw}}\right)$ above the assumed level of effective quiet (124 dB re $1 \mu \mathrm{Pa})$. In total, four $(17 \%)$ of the tagged seals were predicted to receive SELcum $\left(\mathrm{M}_{\mathrm{pw}}\right)$ that exceeded the estimated PTS onset threshold of $186 \mathrm{~dB}$ re $1 \mu \mathrm{Pa}^{2} \cdot \mathrm{s}$ for pinnipeds in water exposed to pulsed sounds, and twelve $(50 \%)$ were predicted to exceed the TTS onset threshold of $171 \mathrm{~dB}$ re $1 \mu \mathrm{Pa}^{2} \cdot \mathrm{s}$ (Table II). For the individuals estimated to exceed PTS thresholds, closest approach distances ranged from 3.9 to $6.9 \mathrm{~km}$, and for TTS from 3.9 to $17.0 \mathrm{~km}$ (Table III).
TABLE III. Summary of the closest distance to pile driving $(\mathrm{km})$ and the maximum estimated 24-h cumulative sound exposure level (SELcum; dB re $1 \mu \mathrm{Pa}^{2} \cdot \mathrm{s}$ ) for each tagged seal, including the unweighted SELcum, $\mathrm{M}_{\mathrm{pw}}$ weighted SELcum (Southall et al., 2007), and PCW weighted SELcum (Southall et al., 2019). The asterisk (*) highlights SELcums exceeding onset thresholds for TTS and double-asterisk (**) for those exceeding onset thresholds for PTS (please note there are no PTS thresholds for the unweighted SELcums).

\begin{tabular}{|c|c|c|c|c|}
\hline $\begin{array}{l}\text { Seal reference } \\
\text { number }\end{array}$ & $\begin{array}{l}\text { Closest distance } \\
\text { to piling }(\mathrm{km})\end{array}$ & Unweighted & $\begin{array}{c}\quad \mathrm{M}_{\mathrm{pw}} \\
\text { weighted }\end{array}$ & $\begin{array}{c}\text { PCW } \\
\text { weighted }\end{array}$ \\
\hline pv40-268-12 & 3.9 & $194^{*}$ & $191^{* *}$ & $174^{*}$ \\
\hline pv40-270-12 & 40.4 & - & - & - \\
\hline pv42-162-12 & 9.3 & 184 & $182^{*}$ & 165 \\
\hline pv42-165-12 & 6.9 & 191 & $189^{* *}$ & $170 *$ \\
\hline pv42-194-12 & 26.9 & 172 & 170 & - \\
\hline pv42-198-12 & 29.9 & - & - & - \\
\hline pv42-220-12 & 34.2 & - & - & - \\
\hline pv42-221-12 & 25.3 & 166 & 163 & 134 \\
\hline pv42-266-12 & 24.9 & 154 & 152 & - \\
\hline pv42-277-12 & 4.7 & $200^{*}$ & $197^{* *}$ & $179^{*}$ \\
\hline pv42-287-12 & 38.7 & - & - & - \\
\hline pv42-288-12 & 15.7 & 170 & 169 & 148 \\
\hline pv42-289-12 & 27.5 & - & - & - \\
\hline pv42-290-12 & 16.9 & 176 & $174^{*}$ & 155 \\
\hline pv42-291-12 & 14.0 & 177 & $175^{*}$ & 158 \\
\hline pv42-292-12 & 34.8 & 153 & 150 & - \\
\hline pv42-293-12 & 17.0 & 176 & $174^{*}$ & 156 \\
\hline pv42-294-12 & 30.7 & 159 & 157 & - \\
\hline pv42-295-12 & 11.3 & 187 & $185^{*}$ & 167 \\
\hline pv42-316-12 & 5.8 & 186 & $184^{*}$ & 165 \\
\hline pv42-317-12 & 17.0 & 185 & $183^{*}$ & 164 \\
\hline pv42-318-12 & 13.8 & 184 & $182^{*}$ & 164 \\
\hline pv42-319-12 & 21.7 & 166 & 164 & - \\
\hline pv42-320-12 & 5.0 & $194^{*}$ & $192^{* *}$ & $176^{*}$ \\
\hline
\end{tabular}

Predicted maximum PCW-weighted SELcum (Southall et al., 2019) ranged from 134 to $179 \mathrm{~dB}$ re $1 \mu \mathrm{Pa}^{2} \cdot \mathrm{s}$ (Table III). Ten $(42 \%)$ of the seals did not receive SELss (PCW) above the assumed level of effective quiet $(124 \mathrm{~dB}$ re 1 $\mu \mathrm{Pa})$. None of the tagged seals were predicted to receive SELcum (PCW) that exceeded the estimated PTS onset threshold $\left(185 \mathrm{~dB}\right.$ re $\left.1 \mu \mathrm{Pa}^{2} \cdot \mathrm{s}\right)$, and four (17\%) were predicted to exceed the TTS onset threshold $(170 \mathrm{~dB}$ re 1 $\left.\mu \mathrm{Pa}^{2} \cdot \mathrm{s}\right)$ for phocids in water exposed to impulsive sounds (Table II). For each of these four seals estimated to exceed TTS thresholds, closest approach distances to piling ranged from 3.9 to $6.9 \mathrm{~km}$ (Table III).

\section{Changes in seal density in relation to pile driving}

During piling, seal density was predicted to significantly decrease (defined as when the upper $\mathrm{CI}$ is a negative percentage change in density) within $25 \mathrm{~km}$ of the wind farm site by both cumulative [Fig. 2(a)] and annulus [Fig. 2(b)] approaches. This decrease was detected in all $5 \mathrm{~km}$ distance bands (annulus) out to $25 \mathrm{~km}$ [Fig. 2(b)]. There was no significant change in density detected beyond this distance, considering either cumulative or annulus zones. The predicted change in density (and confidence intervals) of the 


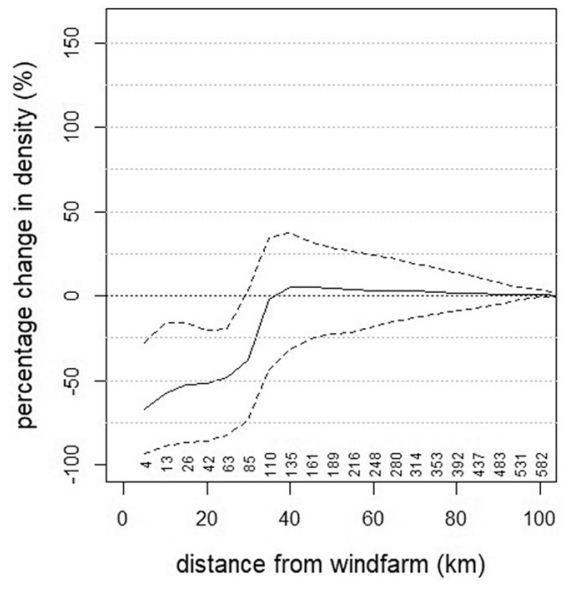

(a)

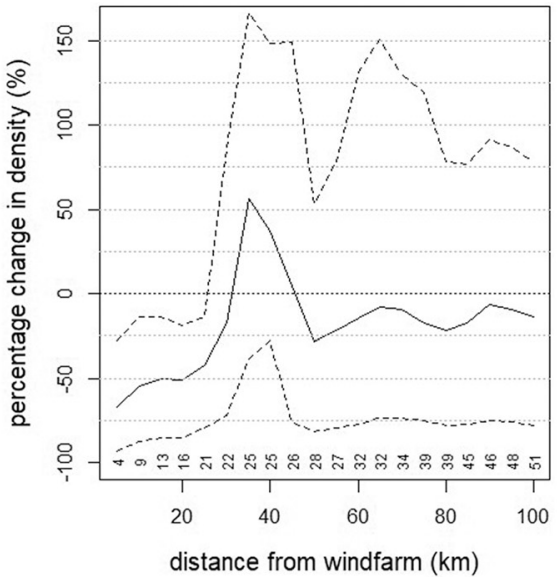

(b)

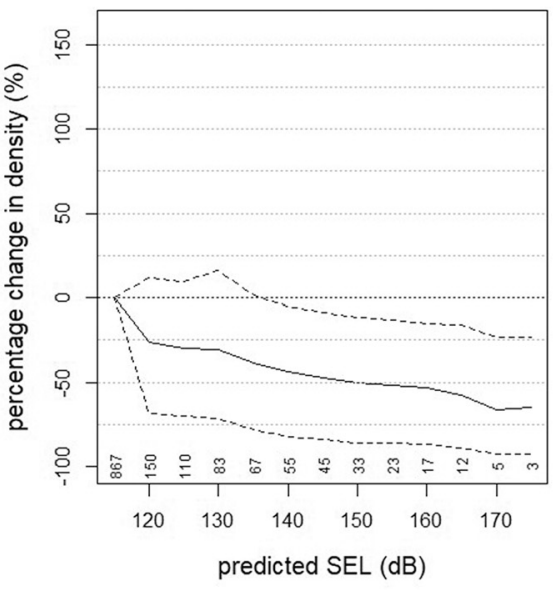

(c)

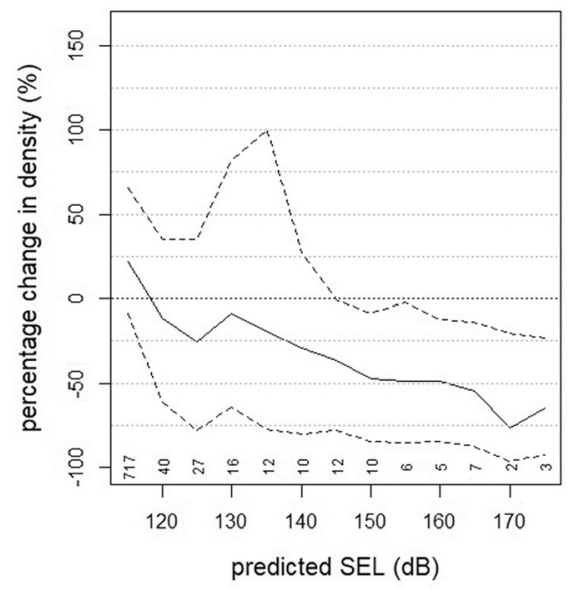

(d)

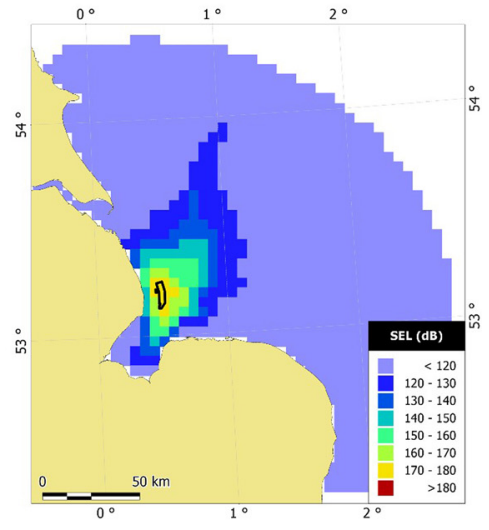

(e)

FIG. 2. (Color online) Predicted changes in seal density as a function of distance from the centre of the wind farm (a-b) and estimated sound exposure level (c-d) (SEL, dB re $1 \mu \mathrm{Pa}^{2} \cdot \mathrm{s}$ ), with SEL averaged across all water depths and piles. (a) Seal density in cumulative zones of increasing distance: plotted density change at distance $\boldsymbol{x}$ is the change in all spatial cells $\leq \boldsymbol{x} \mathrm{km}$ [as presented in Russell et al. (2016)]. (b) Seal density in annulus $5 \mathrm{~km}$ increments: plotted density change at distance $\boldsymbol{x}$ is the change in all spatial cells between $\boldsymbol{x}-5$ and $\boldsymbol{x} \mathrm{km}$. (c) Seal density in cumulative zones of received sound level: plotted density change at SEL $\boldsymbol{x}$ is the change in all spatial cells $\geq \boldsymbol{x}$ dB. (d) Seal density in annulus $5 \mathrm{~dB}$ increments: plotted density change at SEL $\boldsymbol{x}$ is the change in all spatial cells between $\boldsymbol{x}$ and $\boldsymbol{x}+5 \mathrm{~dB}$. Annotations denote the number of spatial grid cells in each distance/SEL category. The dashed lines represent $95 \%$ confidence intervals. The corresponding predicted SELs across the study area (averaged across depths and piles) are shown in (e).

cumulative approach [Fig. 2(a)] converged toward zero as the largest zone considered encompassed almost the entire study area (all cells within $100 \mathrm{~km}$ of the wind farm) and so there would be no overall change in density (percentage of seals).

Seal density was also predicted to decline with increased received sound levels [Figs. 2(c) and 2(d)]. Using the first metric (mean SELss across depths and piles), the cumulative approach revealed significant declines when all cells $\geq 140 \mathrm{~dB}$ re $1 \mu \mathrm{Pa}^{2} \cdot \mathrm{s}$ are considered [Fig. 2(c)]; however, when each received level zone is considered separately (annulus), declines are only detected in each $5 \mathrm{~dB}$ zone above $145 \mathrm{~dB}$ re $1 \mu \mathrm{Pa}^{2} \cdot \mathrm{s}$ [Fig. 2(d), Table V]. There was substantial variation in the predicted SELss [Figs. S2-S5(c)] with depth and pile considered, and thus in the resulting percentage change in density-SELss relationship [Figs. S2-S5(a) and S2-S5(b)]. Due to the variation in these relationships, there was also variation in the SELss threshold above which a significant decline in seal density would be predicted (Table IV). Indeed, considering the lower 95\% CI across piles (averaged across depths) revealed no clear relationship with seal density for annulus zones (Fig. S2). In contrast, the upper $95 \%$ across piles revealed a significant decrease in density for all annulus zones from $160 \mathrm{~dB}$ re $1 \mu \mathrm{Pa}^{2} \cdot \mathrm{s}$ (Fig. S3). Considering the quietest (Fig. S4) or loudest (Fig. S5) depths separately, there was a significant decrease in density in all annulus zones from 145 and $150 \mathrm{~dB}$ re $1 \mu \mathrm{Pa}^{2} \cdot \mathrm{s}$, respectively. In general, the annulus approaches did not predict significant declines in seal density until higher received SELss levels than the cumulative approach (Table IV). For further information on the variation in predicted density between different piling events and water depths, see Electronic Supporting Information.

\section{DISCUSSION AND CONCLUSIONS}

This study used tracking data from 24 harbour seals near a wind farm construction site (Hastie et al., 2015; 
TABLE IV. Summary of estimated single strike sound exposure levels (SELss, $\mathrm{dB}$ re $1 \mu \mathrm{Pa}^{2} \cdot \mathrm{s}$ ) of pile driving, above which a significant decline in seal density is predicted. Five approaches to combining SELss across piling events and depths are shown, alongside previously published results. Two approaches of summarising corresponding seal density estimates over space are calculated: annulus or cumulative zones (both in $5 \mathrm{~dB}$ increments).

\begin{tabular}{lcc}
\hline \hline & \multicolumn{2}{c}{ Approach } \\
\cline { 2 - 3 } & Annulus & Cumulative \\
\hline Mean (averaged across depths and piles) & 145 \\
(1) Mean & 140 \\
Comparison across piles (averaged across depths) & \\
(2) Lower 95\% CI of piles & No clear relationship & 145 \\
(3) Upper 95\% CI of piles & 160 & 150 \\
Comparison across depths (averaged across piles) & 130 \\
(4) Quietest depth & 145 & 140 \\
(5) Loudest depth & 150 & 140 \\
Russell et al. (2016) (averaged across piles) & 155 \\
Quietest depth & - & 140 \\
Loudest depth & - & \\
\hline \hline
\end{tabular}

Russell et al., 2016) to explore four questions in relation to the sensitivity of predicted sound exposures, auditory damage, and changes in seal density to a range of commonly used techniques and assumptions. (1) We found marked differences in the numbers of seals predicted to suffer auditory damage depending upon the choice of weighting functions and thresholds (between $13 \%$ and $50 \%$, and between $0 \%$ and $17 \%$ of seals were predicted to exceed TTS and PTS thresholds, respectively). (2) Predictions of seal density during pile driving, as a function of both distance and predicted received levels, differed between the use of cumulative versus annulus zones. We recommend that future studies use annulus zones, and impact assessments use the results from the annulus predictions (Table V). (3 and 4) The relationship between changes in seal density and predicted received level varied markedly depending on how variations in pile installation and water depth were accounted for. These findings have implications for the use of results from such studies (Hastie et al., 2015; Russell et al., 2016) by policy makers and regulators. In particular, we have found that the choice of method can lead to different estimates of effects and therefore different recommendations for future regulation.

The use of each weighting function resulted in marked differences in estimated SELcum on harbour seals. Specifically, unweighted SELcums from pile driving were highest (up to $200 \mathrm{~dB}$ re $1 \mu \mathrm{Pa}^{2} \cdot \mathrm{s}$ ), $\mathrm{M}_{\mathrm{pw}}$-weighted SELcums (Southall et al., 2007) were intermediate (up to $197 \mathrm{~dB}$ re 1 $\mu \mathrm{Pa}^{2} \cdot \mathrm{s}$ ), and PCW-weighted SELcums (Southall et al., 2019) were lowest (up to $179 \mathrm{~dB}$ re $1 \mu \mathrm{Pa}^{2} \cdot \mathrm{s}$ ). This is to be expected given the differences in the each of the weighting functions. The approach developed by Southall et al. (2007) was designed as relatively conservative initial guidance and the $\mathrm{M}_{\mathrm{pw}}$ weighting function was therefore flat across the hearing range frequencies of each functional species group. For seals exposed to pile driving sounds in the current study, this resulted in SELcums $\left(\mathrm{M}_{\mathrm{pw}}\right)$ that are only $\sim 1-3 \mathrm{~dB}$ lower than unweighted values. More recent guidance uses information from new auditory damage studies to develop a series of updated weighting functions for each functional species group (Southall et al., 2019). This resulted in SELcum (PCW) levels that were $\sim 20-35 \mathrm{~dB}$ lower than unweighted values.

Correspondingly, the differences in acoustic exposures between the $\mathrm{M}_{\mathrm{pw}}$ and PCW weighting functions led to variation in the percentage of seals predicted to receive SELcums exceeding published TTS (50\% vs 17\%) and PTS (17\% vs $0 \%$ ) thresholds. Using an unweighted threshold, a predicted $13 \%$ of individuals exceeded values associated with TTS; no PTS thresholds are available for unweighted pulsed sounds. These results from individual seals exposed to sound broadly reflect the conditions simulated in Faulkner et al. (2019), with the Southall et al. (2019) criteria resulting in markedly lower effects ranges for auditory damage from pile driving sounds.

TABLE V. Predictions of seal density (and changes in seal density) during piling and breaks in piling. Seal densities are presented for each predicted sound exposure level (SELss) category (annulus), along with the number of spatial grid cells corresponding to each SELss category. SELss were averaged across all water depths and piling events. Values in bold denote significant changes (confidence intervals not containing $0 \%$ change in density).

\begin{tabular}{|c|c|c|c|c|c|c|c|c|}
\hline \multirow[b]{2}{*}{ SELss $\left(\mathrm{dB}\right.$ re $\left.1 \mu \mathrm{Pa}^{2} \cdot \mathrm{s}\right)$} & \multirow[b]{2}{*}{ Number of spatial cells } & \multicolumn{3}{|c|}{ Mean density ( $\%$ of at-sea population) } & \multicolumn{4}{|c|}{ Percentage change in density } \\
\hline & & Non-piling & Piling & Difference & Mean & Median & Lower $95 \% \mathrm{CI}$ & Upper $95 \%$ CI \\
\hline $115-120$ & 717 & 53.91 & 65.94 & 12.03 & 22.31 & 20.26 & -8.96 & 65.95 \\
\hline $120-125$ & 40 & 8.77 & 7.79 & -0.98 & -11.21 & -12.54 & -61.26 & 35.14 \\
\hline $125-130$ & 27 & 5.53 & 4.11 & -1.42 & -25.60 & -29.44 & -78.16 & 35.27 \\
\hline $130-135$ & 16 & 8.82 & 8.08 & -0.74 & -8.43 & -13.08 & -64.36 & 82.19 \\
\hline $135-140$ & 12 & 4.62 & 3.71 & -0.91 & -19.65 & -22.19 & -77.47 & 100.36 \\
\hline $140-145$ & 10 & 3.83 & 2.70 & -1.13 & -29.40 & -36.17 & -80.43 & 27.10 \\
\hline $145-150$ & 12 & 3.28 & 2.09 & -1.19 & -36.37 & -40.52 & -77.97 & -0.34 \\
\hline $150-155$ & 10 & 3.59 & 1.89 & -1.70 & -47.31 & -51.46 & -84.70 & -8.56 \\
\hline $155-160$ & 6 & 2.05 & 1.05 & -1.00 & -48.72 & -52.46 & -85.48 & -1.90 \\
\hline $160-165$ & 5 & 2.80 & 1.44 & -1.36 & -48.52 & -54.35 & -84.63 & -12.20 \\
\hline $165-170$ & 7 & 2.10 & 0.96 & -1.14 & $-\mathbf{5 4 . 3 8}$ & -58.67 & -87.73 & -13.64 \\
\hline 170-175 & 2 & 0.08 & 0.02 & -0.06 & -76.26 & -79.27 & -96.04 & -20.32 \\
\hline $175-180$ & 3 & 0.62 & 0.22 & -0.40 & -64.80 & -68.41 & -92.17 & -22.93 \\
\hline
\end{tabular}


These weighting-function specific percentages are lower than previous predictions of auditory damage from pile driving sound exposure. Specifically, using the same seal tag data to that analysed here, Hastie et al. (2015) predicted maximum 24-h SELcum $\left(\mathrm{M}_{\mathrm{pw}}\right)$ values ranging from 171 to $195 \mathrm{~dB}$ re $1 \mu \mathrm{Pa}^{2} \cdot \mathrm{s}$ for individual seals; $50 \%$ of seals were predicted to exceed the PTS onset threshold (compared to $17 \%$ here) and all (100\%) exceeded the TTS threshold (compared to $50 \%$ here). The difference between these results was due to the different sound propagation approaches used, highlighting the clear sensitivity of predicted acoustic exposure and the associated threshold shifts, to the assumptions of commonly used propagation models.

The acoustic modelling approach used here predicts the effects of strike energy and bathymetry, and takes into account more information on the environment and pile driving source [compared to Hastie et al. (2015)]. Whilst this reduces uncertainty, there are still potential sources of variation that are not taken into account. Pile penetration depth can affect the dynamic behaviour of the pile and so could affect the sound produced (de Jong et al., 2019). Here, we assume a homogeneous medium sand seabed and a constant water depth at mean sea level. Although the majority of the study area is of this sediment type, variation in this could increase uncertainty in predictions of received level and associated effects on animals, especially for the lower frequencies modelled $(<1 \mathrm{kHz})$. Assuming a constant water depth is a common approach for acoustic modelling. However, for areas with a strong tidal cycle, it is possible that variation in propagation conditions over the tidal cycle (and associated water depths) could be considerable. Investigation into this variation across tidal cycles would be a useful avenue for future research, although whether it would be computationally feasible to integrate this into individual impact studies is unclear. The uncertainties associated with the Aquarius modelling approach are discussed further in de Jong et al. (2019). Comparisons of the model estimates with a series of measurements from opportunistic boat-based hydrophones and a moored recorder suggests that the error in model estimates is approximately $4 \mathrm{~dB}$ re $1 \mu \mathrm{Pa}^{2} \cdot \mathrm{s}$. The boat-based recordings made near the water surface $(\sim 1 \mathrm{~m})$ all measured lower SELss than the model predictions for the shallowest depth bin $(2.5 \mathrm{~m})$. Whilst not a formal validation, this comparison highlights the potential uncertainty of received levels near the surface, and the performance of the model for estimating near surface piling noise (although the comparison is only made above the modelled depths). Received levels near the surface are highly variable due to interference patterns, sound speed profile ducts, and waves, and measurements are likely to be sensitive to environmental conditions such as wind and wave activity. The measurements from the moored recorder at $\sim 9 \mathrm{~m}$ below the surface provided a close match to the model predictions. The conditions at these depths are more representative of the majority of the water column, as variability in propagation conditions is much less.

Here we extended the potential utility of the results from Russell et al. (2016) by presenting changes in seal density as a function of annulus zones of distance and five metrics of predicted received level. Using annulus distance zones confirmed significant decreased density up to $25 \mathrm{~km}$ from the centre of the windfarm [as found using cumulative distance zones; Russell et al. (2016)]. To compare overall seal distribution between piling and non-piling (a binary comparison), it was necessary to generate one received level per cell (across all 27 pile installations and water depths). Russell et al. (2016), using cumulative zones, predicted a significant decrease in seal density from received levels (averaged across all installations) above $140-155 \mathrm{~dB}$ re 1 $\mu \mathrm{Pa}^{2} \cdot \mathrm{s}$, based on the quietest and loudest part of the water column. Here, we show these levels are affected both by the sound propagation model used (130-140 dB re $1 \mu \mathrm{Pa}^{2} \cdot \mathrm{s}$ for quietest-loudest depths, cumulative), and the use of annulus rather than cumulative zones $\left(145-150 \mathrm{~dB}\right.$ re $1 \mu \mathrm{Pa}^{2} \cdot \mathrm{s}$ for quietest-loudest depths, annulus) (Table IV). Examining the variation in SELss across pile installations (95\% CIs) revealed substantial variation in the level of significant decrease in density; indeed, only for the upper 95\% CI could a significance level be quantified (Table IV). Annulus zones (especially at larger distances/lower received levels) show wider confidence intervals for changes in density than for cumulative zones. This is due to the increasing sample size associated with the increasing size of cumulative zones; the change will converge on zero change in percentage density as the cumulative zones encompass an increasing proportion of the study area. Additionally, the received levels at which there is a significant predicted effect on seal density are lower for the cumulative approach. The cumulative method always includes the zones of highest exposure (and potential effect on behaviour), and so this likely enables the overall density change to be detected further from the wind farm.

Here, we illustrated how the predicted SELss associated with significant decreases in seal density varies across pile installations and depth. However, there are other sources of variation that we did not account for. For instance, we only considered the average maximum piling energy reached over all piling events $(2000 \mathrm{~kJ})$ and not the received levels from each piling strike with potentially different sequences of piling energies. There may also be changes in the seafloor between piling sites and potentially equipment changing the source spectrum of different piling strikes. Linking population level responses to a particular sound level necessitates averaging over a wide range of possible situations, including different external conditions (e.g., piling ramp-up sequence, time of day), and differences between and within individual animals (e.g., behavioural state, previous exposure history). These differences may increase variability in predicted responses. Considering only the average (population-level) response makes it challenging to identify factors which might make animals more or less responsive to sound, information which could be used in future assessments of noise impacts.

In summary, we use tracking data on wild harbour seals exposed to pile driving sounds to update quantitative estimates of effects on seal hearing and behaviour. The findings 
of Hastie et al. (2015) and Russell et al. (2016) remain amongst the few studies quantifying the effects of pile driving on seals; as such, they are widely used in EIAs. While we recognise the contribution these findings make, it is important that researchers, regulators, policy makers, and industry recognise the inherent limitations associated with studies predicting auditory damage and population level redistribution. Auditory damage in marine mammals is a rapidly evolving field of research (Kastelein et al., 2018; Southall et al., 2019), and this current study demonstrates the importance of updating the predictions as new information becomes available. It also illustrates the sensitivity and limitations of predictions made with commonly used acoustic propagation models. We recommend future studies, where possible, carry out a spatially diverse set of acoustic measurements to calibrate and hence reduce the uncertainties associated with the acoustic source and propagation modelling. These acoustic measurements should be used to monitor noise levels during construction and help characterise the variation in sound produced from different strike energies. Efforts should be made to validate sound propagation models in the environment and conditions they are proposed to be used in, for both impact assessments and scientific studies. In particular, these measurements should focus on the expected location and conditions (depth, habitat) of the study population. Underwater noise monitoring is often a requirement of consent for offshore wind farm projects and, as such, should enable model verification across a large range of environments and pile types. Researchers should also endeavour to publish updated predictions of auditory damage following Southall et al. (2019). A clear avenue for future work would be to validate these types of predictions through the collection of auditory threshold information pre- and post-exposure to pile driving; this could potentially be carried out on wild seals using auditory evoked potential measurements (Wolski et al., 2013) or in a captive environment using controlled exposures and psychophysical methods [e.g., Kastak et al. (2005); Kastelein et al. (2012)].

Population-level redistribution studies are a key first step in determining the presence and magnitude of potential effects, and the time to recovery (to pre-disturbance distribution). Researchers should make their findings as applicable as possible for use by stakeholders (e.g., using annulus rather than cumulative zones in quantitative EIA analyses). In particular, relating changes in density to distance from a source can improve understanding of the potential implications of avoidance [in terms of collision risk (e.g., tidal turbines), barrier effects and loss of habitats or resources]. However, there are a number of important caveats associated with population level redistribution studies. For example, it is not clear whether these changes in density are a result of more animals leaving the area, less new animals entering the area, or a combination of both. Such studies necessarily combine multiple potential disturbance events and animal responses, and here we showed that these also encompass a wide range of potential received levels.
With developments of tracking technology and onanimal long-term sound recordings [e.g., Mikkelsen et al. (2019)], information on individual behaviour and sound exposure is rapidly improving. Analytical tools [e.g., DeRuiter et al. (2013); Quick et al. (2017)] to model such data mean that studies of responses to sound are no longer restricted to considering population-level distribution patterns. A useful avenue for future research would be to investigate how individual seals respond to sound exposure. Studying behaviour of individuals may provide greater insight into the mechanisms behind the population-level patterns seen and enable us to quantify dose-response relationships taking into account the variability between individuals. This will ultimately improve efforts to extrapolate and model effects at the population level.

\section{ACKNOWLEDGMENTS}

This paper was part of work presented at the fifth International Meeting on The Effects of Noise on Aquatic Life held in Den Haag (The Netherlands), July 2019, and we are grateful for the Rodney Coates award given to KFW for the presentation of this project at the conference. We also thank the editor and two anonymous reviewers whose insightful comments greatly improved the paper. Data collection was funded as part of the Department of Energy and Climate Change's (now Department of Business, Energy and Industrial Strategy) Offshore Energy Strategic Environmental Assessment programme, with additional resources from National Capability funding from the Natural Environment Research Council to the Sea Mammal Research Unit (Grant No. SMRU1001). Sound propagation modelling and subsequent analyses were funded by Race Bank Offshore Wind Farm Ltd. KFW was funded by University of St Andrews and the Department of Business, Energy and Industrial Strategy, as part of a PhD studentship.

\footnotetext{
${ }^{1}$ See supplementary material at https://doi.org/10.1121/10.0001408 for further plots of estimated sound exposure, seal density, acoustic measurements, and details of tagged individuals.
}

Ainslie, M. A. (2010). Principles of Sonar Performance Modelling (Springer-Praxis, Chichester, UK).

Bailey, H., Brookes, K. L., and Thompson, P. M. (2014). "Assessing environmental impacts of offshore wind farms: Lessons learned and recommendations for the future," Aquat. Biosyst. 10, 1-13.

Bailey, H., Senior, B., Simmons, D., Rusin, J., Picken, G., and Thompson, P. M. (2010). "Assessing underwater noise levels during pile-driving at an offshore windfarm and its potential effects on marine mammals," Mar. Pollut. Bull. 60, 888-897.

Bivand, R., Keitt, T., Rowlingson, B., and Pebesma, E. (2014). "rgdal: Bindings for the geospatial data abstraction library," $\mathrm{R}$ package version 0.8-16.

Bivand, R., and Lewin-Koh, N. (2017). "maptools: Tools for reading and handling spatial objects," $\mathrm{R}$ package version 0.9-2. Retrieved from https://cran.r-project.org/package=maptools (Last viewed 1 June 2018).

Breton, S. P., and Moe, G. (2009). "Status, plans and technologies for offshore wind turbines in Europe and North America," Renew. Energy 34, 646-654.

de Jong, C., Binnerts, B., Prior, M., Colin, M., Ainslie, M., Mulder, I., and Hartstra, I. (2019). "Wozep-WP2: Update of the Aquarius models for marine pile driving sound predictions," TNO Rep. (2018), No. R11671, The Hague, Netherlands, p. 94. Retrieved from 
https://www.noordzeeloket.nl/publish/pages/160801/update_aquarius_models_ pile_driving_sound_predeictions_tno_2019.pdf (Last viewed 1 August 2019).

Deeks, A. J., and Randolph, M. F. (1993). "Analytical modelling of hammer impact for pile driving," Int. J. Numer. Anal. Methods Geomech. 17, 279-302.

DeRuiter, S. L., Southall, B. L., Calambokidis, J., Zimmer, W. M. X., Sadykova, D., Falcone, E. A., Friedlaender, A. S., Joseph, J. E., Moretti, D., Schorr, G. S., Thomas, L., and Tyack, P. L. (2013). "First direct measurements of behavioural responses by Cuvier's beaked whales to midfrequency active sonar," Biol. Lett. 9, 20130223.

Faulkner, R. C., Farcas, A., and Merchant, N. D. (2019). "Risk assessment of permanent auditory injury in marine mammals: Differences arising from the application of the Southall and NOAA criteria," Scottish Marine and Freshwater Science Report (Marine Scotland Science, Edinburgh), Vol. 10, No. 1.

Finneran, J. J. (2015). "Noise-induced hearing loss in marine mammals: A review of temporary threshold shift studies from 1996 to 2015," J. Acoust. Soc. Am. 138, 1702-1726.

Hastie, G. D., Russell, D. J. F., McConnell, B., Moss, S., Thompson, D., and Janik, V. M. (2015). "Sound exposure in harbour seals during the installation of an offshore wind farm: Predictions of auditory damage," J. Appl. Ecol. 52, 631-640.

Hijmans, R. J. (2017). "raster: Geographic data analysis and modeling," R package version 2.6-7. Retrieved from https://cran.r-project.org/package= raster (Last viewed 1 June 2018).

Iliffe, J. C., Ziebart, M. K., Turner, J. F., Talbot, A. J., and Lessnoff, A. P. (2013). "Accuracy of vertical datum surfaces in coastal and offshore zones," Surv. Rev. 45, 254-262.

Kastak, D., Southall, B. L., Schusterman, R. J., and Kastak, C. R. (2005). "Underwater temporary threshold shift in pinnipeds: Effects of noise level and duration," J. Acoust. Soc. Am. 118, 3154-3163.

Kastelein, R. A., Gransier, R., Hoek, L., Macleod, A., and Terhune, J. M. (2012). "Hearing threshold shifts and recovery in harbor seals (Phoca vitulina) after octave-band noise exposure at $4 \mathrm{kHz}$," J. Acoust. Soc. Am. 132, 3525-3537.

Kastelein, R. A., Helder-Hoek, L., Kommeren, A., Covi, J., and Gransier, R. (2018). "Effect of pile-driving sounds on harbor seal (Phoca vitulina) hearing," J. Acoust. Soc. Am. 143, 3583-3594.

Mikkelsen, L., Johnson, M., Wisniewska, D. M., van Neer, A., Siebert, U., Madsen, P. T., and Teilmann, J. (2019). "Long-term sound and movement recording tags to study natural behavior and reaction to ship noise of seals," Ecol. Evol. 9, 2588-2601.

Nedwell, J. R., Brooker, A. G., and Barham, R. J. (2011). "Measurement and assessment of underwater noise during impact piling operations at the Lincs offshore wind farm," Subacoustech Environmental Report No. E273R0203

NMFS (2016). "Technical guidance for assessing the effects of anthropogenic sound on marine mammal hearing: Underwater acoustic thresholds for onset of permanent and temporary threshold shifts," U.S. Dept. of Commer., NOAA. NOAA. Technical Memorandum NMFS-OPR-55, 178 pages.
NMFS (2018). "2018 Revisions to: Technical guidance for assessing the effects of anthropogenic sound on marine mammal hearing (Version 2.0): Underwater thresholds for onset of permanent and temporary threshold shifts," U.S. Dept. of Commer., NOAA. NOAA Technical Memorandum NMFS-OPR-59, 167 pages.

Pebesma, E., and Bivand, R. S. (2005). "S classes and methods for spatial data: The sp package," R package version 2.01-40.

Porter, M. B. (2001). "The KRAKEN normal mode program," SACLANT Undersea Research Centre, 207 pages. Retrieved from http://oalib. hlsresearch.com/Modes/kraken.pdf (Last viewed 1 October 2019).

Quick, N., Scott-Hayward, L., Sadykova, D., Nowacek, D., and Read, A. (2017). "Effects of a scientific echo sounder on the behavior of shortfinned pilot whales (Globicephala macrorhynchus)," Can. J. Fish. Aquat. Sci. 74, 716-726.

$\mathrm{R}$ Core Team (2019). "R: A language and environment for statistical computing," Vienna, Austria. Retrieved from https://www.r-project.org (Last viewed 1 October 2019).

Russell, D. J. F., Brasseur, S. M. J. M., Thompson, D., Hastie, G. D., Janik, V. M., Aarts, G., McClintock, B. T., Matthiopoulos, J., Moss, S. E. W., and McConnell, B. (2014). "Marine mammals trace anthropogenic structures at sea," Curr. Biol. 24, R638-R639.

Russell, D. J. F., Hastie, G. D., Thompson, D., Janik, V. M., Hammond, P. S., Scott-Hayward, L. A. S., Matthiopoulos, J., Jones, E. L., and McConnell, B. J. (2016). "Avoidance of wind farms by harbour seals is limited to pile driving activities," J. Appl. Ecol. 53, 1642-1652.

Sehgal, A., Tumar, I., and Schönwälder, J. (2009). "Variability of available capacity due to the effects of depth and temperature in the underwater acoustic communication channel," IEEE Ocean. 2009- Eur., 1-6 pages.

Sharples, R. J., Moss, S. E., Patterson, T. A., and Hammond, P. S. (2012). "Spatial variation in foraging behaviour of a marine top predator (Phoca vitulina) determined by a large-scale satellite tagging program," PLoS One 7, e37216.

Southall, B. L., Bowles, A. E., Ellison, W. T., Finneran, J. J., Gentry, R. L., Greene, C. R., Kastak, D., Jr., Ketten, D. R., Miller, J. H., Nachtigall, P. E., Richardson, W. J., Thomas, J. A., and Tyack, P. L. (2007). "Marine mammal noise exposure criteria: Initial scientific recommendations," Aquat. Mamm. 33, 411-521.

Southall, B. L., Finneran, J. J., Reichmuth, C., Nachtigall, P. E., Ketten, D. R., Bowles, A. E., Ellison, W. T., Nowacek, D. P., and Tyack, P. L. (2019). "Marine mammal noise exposure criteria: Updated scientific recommendations for residual hearing effects," Aquat. Mamm. 45, 125-232.

Thompson, P. M., Hastie, G. D., Nedwell, J., Barham, R., Brookes, K. L., Cordes, L. S., Bailey, H., and McLean, N. (2013). "Framework for assessing impacts of pile-driving noise from offshore wind farm construction on a harbour seal population,” Environ. Impact Assess. Rev. 43, 73-85.

WindEurope (2019). "Offshore wind in Europe: Key trends and statistics 2018," Brussels, Belgium, 1-37 pages.

Wolski, L. F., Anderson, R. C., Bowles, A. E., and Yochem, P. K. (2013). "Measuring hearing in the harbor seal (Phoca vitulina): Comparison of behavioral and auditory brainstem response techniques," J. Acoust. Soc. Am. 113, 629-637. 